Research Article

\title{
Practice of EVA-Based Balanced Scorecard in the Construction of Performance Evaluation System
}

\author{
Dongwen Xie and Hui Deng \\ College of Accounting, Zhanjiang Science and Technology College, Zhanjiang 524094, Guangdong, China \\ Correspondence should be addressed to Hui Deng; 17125774@cumt.edu.cn
}

Received 25 May 2021; Revised 16 June 2021; Accepted 6 July 2021; Published 21 July 2021

Academic Editor: Sang-Bing Tsai

Copyright (c) 2021 Dongwen Xie and Hui Deng. This is an open access article distributed under the Creative Commons Attribution License, which permits unrestricted use, distribution, and reproduction in any medium, provided the original work is properly cited.

\begin{abstract}
In the current era of new economy, the competition between enterprises is becoming increasingly fierce. In many performance evaluation tools, EVA's balance sheet scorecard has gradually become a more convenient management tool for organizations to implement strategies. The introduction of a balanced scorecard (if used properly) in the company's performance evaluation will greatly improve the management efficiency of the organization and play a better role in promoting the enterprise to achieve the best resource allocation. This article aims to analyze the status quo of the EVA balanced scorecard in the performance appraisal system and its implementation in the enterprise through an overview of the relevant concepts and basic theories such as the balanced scorecard, combined with the theory of enterprise performance evaluation, such as the balanced scorecard. And strategic performance evaluation theory and other related theories established a series of effective management methods that match the EVA balanced scorecard. Use performance management system model calculation and performance evaluation system design to study the role of EVA-based balanced scorecard in building the performance evaluation system. Exploring the EVA balanced scorecard through experimental research can not only really improve the shortcomings and problems of the single performance appraisal system used by enterprises but also make it more in line with the company's strategic development requirements and promote the realization of the strategy. The goal of the company: the experimental results of this paper show that $80 \%$ of the company's operating conditions in the EVA-based balanced points performance evaluation have increased year by year and also confirmed that the EVA performance management system is a future-oriented performance management system.
\end{abstract}

\section{Introduction}

At present, the market economy situation is full of many unknowns, the growth rate of the world economy slows down, and the growth and development of real enterprises are full of variables. As far as circulation is concerned, the policy support provided by the government can help stimulate, but it will also exceed the purchasing power of the consumer market in advance. The market volatility in recent years will be very large. In this economic environment, only by changing the internal performance evaluation system, the company can stimulate business vitality to a greater extent, improve the company's internal competitiveness, create differentiated advantages, seek more room for growth, and maximize its value. Economic value-added cards and balance scores are both effective tools for evaluating company performance. After the in-depth development of the balanced scorecard, its application scope is expanding, and some enterprises also began to gradually use the balanced scorecard for enterprise performance evaluation. However, the setting of the evaluation index is not reasonable, and the implementation effect is not good. In order to design the performance evaluation system reflecting the actual business effect of enterprises, it is very necessary to combine it with the actual operation situation of enterprises.

This article establishes that a comprehensive EVA balanced scorecard to improve the corporate performance evaluation system is very important. It can not only improve the shortcomings and deficiencies of a single performance appraisal system and better exert the effect of performance appraisal but also make performance appraisal more in line with the company's strategic development requirements 
from the selection and design of key performance indicator strategies. Strategically, it improves the overall and promotes the realization of strategic goals. EVA can be used as an indicator to measure the performance and value of an enterprise to make up for deficiencies and reflect the true status of the enterprise. The index reflected by EVA tends to maximize the value of the company, which is the same as the interests of the company's managers and shareholders, providing more reference value for the rights and interests of enterprises. And EVA pays more attention to the healthy and lasting development of enterprises, avoiding long-term profits in exchange for immediate short-term profits. Therefore, this article uses EVA to represent the company's performance and value to make the research more valuable. With the idea of EVA becoming more and more popular and the comprehensive promotion of EVA performance evaluation by SASAC, EVA has gradually become an important tool. Today's hot financial indicators, but with the introduction of new indicators, will certainly be accompanied by a variety not in line with the actual situation of China's enterprises. It is a matter of the international situation. Stenster's EVA calculation adjustment project involves more than 160 items. After each item is adjusted, the result is the most accurate, but the cost is also huge, which is not consistent with the actual situation. The principle of comprehensive cost-effectiveness: secondly, the EVA formulas of SASAC and Guotai'an are for all industries; obviously, this is not in line with the principle of realistic logic.

EVA has been used for a long time in the development of the world economy, and the current domestic enterprise market has generated great interest in it. The theoretical community has begun to conduct a lot of research on it, and many companies have also begun to implement it in the real world. It is used as the core of the corporate performance evaluation system. Berlot believes that the combination of accounting foundation and EVA evaluation value is not a short-term goal, but a performance evaluation indicator that focuses on long-term development. This indicator can truly reflect the business performance of the company, but there is no specific direction [1]. Carter analyzed the EVA content by researching statistical literature and analyzing the history of EVA research by local researchers and looked forward to the future research trends. He believes that the EVA implementation process, related salary design, cross-random research, and detailed research are carried out on the EVA model applicable to China's national conditions, but there is a lack of specific experimental data [2]. Maltz believes that the advantages and disadvantages of EVA performance evaluation indicators have been analyzed. The introduction of EVA can improve the management structure of enterprises, establish the concept of capital cost, increase utilization rate, and promote investment decision-making. However, EVA has its limitations and may not reflect the company's cash flow; therefore, EVA should be calculated according to the data of financial statements. When state- owned enterprises make information public, the corresponding EVA balanced scorecard in the accounting statements will be adjusted to the research and survey data applied by the company, but this will cause the reliability of EVA to decrease [3].

The innovation of this article is to analyze the use of EVA as a substitute for other performance indicators in this article and conduct research on companies that use EVA. EVA is different from our traditional accounting indicators that represent corporate earnings. EVA reflects the business performance and value of the company from a new perspective. Its concept brings the interests of the company's shareholders and management closer together. It solves some shortcomings of traditional accounting indicators and pays more attention to the healthy and sustainable development of enterprises. Therefore, this article uses EVA to replace traditional accounting indicators to explore the relationship with external financing structures.

\section{EVA Performance Evaluation System Model}

2.1. Principle Analysis of EVA Performance Evaluation. EVA refers to the remaining profit after deducting the cost of capital invested in operating income $[3,4]$. The essence of economic benefits is the income of the company, which can measure the company's benefits and performance more accurately, so as to more accurately reflect the value creation or value destruction of the company in different ways [5]. The calculation formula is EVA = net operating profit after capital occupation after $\operatorname{tax} *$ weighted average cost of capital ratio. The main data source of the EVA performance management system is the financial indicators of the enterprise. Through the organic integration of corporate financial indicators and technical processing, value drivers classify corporate financial indicators $[6,7]$. These data can be divided into tactical level, strategic level, and business level [8]. At the same time, compared with the related enterprise value growth method, the economic added value of the enterprise and the EVA index of the enterprise can be obtained. Finally, the performance management system realized by the EVA index of the enterprise is called the EVA performance management system [9].

2.2. Determine the Model Weight Coefficient. EVA is a performance measurement standard based on the time period operation. Mathematically, it is equal to net operating profit after tax minus the cost of debt and equity $[10,11]$. It can be expressed as the following formula:

$$
\mathrm{EVA}=\mathrm{NOPAT}-K f \times \text { FACC. }
$$

The constructed weight matrix is used to obtain the maximum value of the feature $\lambda$ and the corresponding feature vector $V$. It is the weight of the relative importance of each indicator at the current level and the corresponding 
indicator at the upper level $[12,13]$. This article uses the square root method to find the specific value and specific vector of the judgment matrix and calculates the output of each element of the judgment matrix row:

$$
F_{i}=\prod_{j=1}^{n} a_{i j} .
$$

Calculate the $n$th root of $F$ :

$$
H_{i}=\sqrt[n]{F_{i}}
$$

Normalize the vector $H$ :

$$
V_{i}=\frac{H}{\sum_{i=1}^{n} H_{i}} .
$$

In order to measure the degree of deviation of the judgment matrix from consistency, a specific matrix value must be tested $[14,15]$. The endurance test is used to judge the reasonableness of the weight obtained. If the test passes, the normalized vector is a weight vector; otherwise, it is a negative vector. If it fails, the judgment matrix must be reconstructed into features corresponding to the maximum value of its vector matrix:

$$
\mathrm{BI}=\frac{\lambda_{\max }-n}{n-1} .
$$

2.3. Design of Scoring Method. After determining the weights of different indicators in the rating system, when calculating the scores of different key indicators, due to the different types of rating indicators, it is impossible to directly compare them. The indicator data must be standardized [16]. This paper uses the efficiency coefficient method to first determine the number of standard indicator data to obtain indicator scores [17, 18]. For the superlarge indicators, the efficiency coefficient method can be directly used to calculate the excess work efficiency and recovery rate. For very small indicators (such as the death rate of one million tons), the reciprocal is converted to the maximum value of the efficiency method used for processing $[19,20]$. The specific formula is as follows:

$$
H=a+\frac{F-m}{M-m} \times c .
$$

The overall result of the enterprise performance evaluation is calculated using the comprehensive index method, and the calculation formula is as follows:

$$
F=\sum_{i=1}^{n} H_{i} \theta_{i} .
$$

2.4. EVA Matrix Consistency. The analytic hierarchy process has strong operability and can skillfully combine quantitative and qualitative indicators in decision-making and planning, so its application degree is high. The evaluation index system is composed of environmental quantitative indicators and qualitative indicators such as performance and responsibility. Therefore, the analytic hierarchy process (AHP) is used to construct the evaluation index system and determine the index weight, and the fuzzy comprehensive analysis method is used for a comprehensive evaluation, calculating the consistency ratio FR:

$$
\mathrm{FR}=\frac{\mathrm{FH}}{\mathrm{FH}} \text {. }
$$

When calculating the EVA evaluation index, it needs to be weighted according to the actual capital structure of the enterprise. Therefore, the capital cost level of each enterprise is not consistent. In the case of adopting a uniform average cost of capital rate, it may not be conducive to the operators to optimize the debt financing structure and to make a profit distribution policy that is more conducive to investors; the formula is as follows:

$$
Q=H_{f}+\beta \times\left(H_{m} H_{f}\right) .
$$

2.5. EVA Theoretical Framework. EVA valuation model is based on the concept of EVA. EVA is a kind of business performance evaluation index developed by $S$ TEM STEWARD consulting company in 1933. In Europe and the United States, both famous multinational companies, such as Coca-Cola and Siemens, and many small- and mediumsized enterprises are actively using EVA to evaluate the business performance of enterprises, which has brought good results. The basic connotation of EVA: the balance of the company's adjusted net operating profit after tax minus the opportunity cost of its invested capital (including equity capital and debt capital) is expressed by the following formula:

$$
\mathrm{EVA}=\mathrm{NOPAT}-G_{t} \times H B_{t-1} .
$$

But the cost of equity capital and debt capital is not the actual cost of equity and debt capital, but the opportunity cost of equity and debt capital. The cost of equity capital is determined by the capital asset pricing model, and the cost of debt capital can be determined by the benchmark interest rate of medium- and long-term bank loans with a term of 3-5 years:

$$
\begin{aligned}
\mathrm{ROIC} & =\frac{\mathrm{NOPAT}}{\mathrm{HB}_{t-1}} \\
\mathrm{EVA} & =\left(\mathrm{ROI}-\mathrm{G}_{t}\right) \mathrm{HB}_{t-1} .
\end{aligned}
$$

\section{EVA Performance Management System}

3.1. The Structure of EVA Performance Management System. EVA performance management system is a management system that increases value. Its main management structure can be divided into four different parts according to the value of the enterprise, including performance appraisal system, management system, incentive system, and conceptual system. The first step of the EVA performance evaluation system is the performance evaluation system, 
which is mainly responsible for evaluating the performance of the departments and related personnel related to the EVA performance management system. It is the foundation of the EVA performance evaluation system and the main source of EVA performance data. It is also an indispensable tool for the implementation of the EVA performance evaluation system. The second step is the management system, which scientifically manages the operation of the enterprise through performance evaluation and increases the realization of enterprise value. The third step is the incentive mechanism, which is mainly used to motivate and motivate every employee and every department in the enterprise to work hard to improve the value of the enterprise. The fourth step is the conceptual system, which is a value and code of conduct that goes deep into the heart of every employee of the company and guides every employee and every department of the company to the direction of adding value to the company. In the EVA performance management system, these four modules are interrelated and complementary.

3.2. The Application Status of EVA in My Country. China has now integrated into the wave of the world economy, and its domestic interests have gradually begun to heat up. The theoretical circle has begun to conduct a lot of research, and a large number of companies have begun to regard it as the core of the corporate performance evaluation system in the practice circle. Among them, many well-known enterprises such as Tsingtao Brewery have become the company's successor customers, and enterprise groups such as Huawei Electric Company, Group, and Xuji Group have also begun to implement. Since my country still has some implementation obstacles, such as capital cost barriers, because my country's capital market is still a weak and effective market, it is difficult to determine the required capital cost value capital asset pricing model when using it.

\subsection{Advantages and Disadvantages of EVA}

3.3.1. Advantages of EVA. The cost of capital has been included in the calculation. Calculating the cost of capital to truly reflect the operating results is the most important feature of EVA. Compared with traditional profit indicators, EVA comprehensively includes the various costs of corporate capital in the calculation, and the residual income obtained can be used as the true value-added of the enterprise. EVA pointed out that corporate equity capital is not cheap. If the daily business fails to protect the interests of shareholders, there will be a situation in which shareholders' rights and interests "walk around", leading to shareholders' withdrawal. When income exceeds the cost of all capital, the company is creating value; otherwise, it is destroying value. EVA more accurately reflects the company's business performance and value creation results. Corresponding performance evaluation indicators have also developed from the traditional evaluation basis, which is based on accounting profit as the measurement purpose. Adjusting the company's accounting profits accordingly, all capital costs are evaluated from four dimensions.
3.3.2. Disadvantages of EVA. It does not reflect nonfinancial indicators. The EVA value is completely based on financial information, all of which are historical data, reflecting the residual nature of the company's past operating conditions. And usually, it can only reflect the resultant information but not the process information that led to the result. However, one of the purposes of performance evaluation is to discover the problems and deficiencies in the operation of the enterprise, make timely corrections, and provide forwardlooking guidance for the development of the enterprise. These are often reflected by some nonfinancial information. Only when financial and nonfinancial information are comprehensively incorporated into the performance evaluation system can the value creation of an enterprise be accurately measured, which is not conducive to the longterm development of an enterprise to a certain extent.

\section{Application of EVA in Corporate Performance Evaluation}

4.1. Core Concept of EVA. The core concept of EVA is the cost of capital. The cost of capital refers to the return a company hopes to obtain from the economic decision of investing in currency, including the cost of debt capital and the cost of equity. From an investor's point of view, the cost of capital is the maximum return that an investor may obtain in other investment projects that the investor has abandoned due to investing in the project. From the company's point of view, the cost of capital is another investment project that investors give up by making the most of the capital for profit.

4.2. Company Performance Evaluation Based on EVA. The company calculates after-tax net profit based on the EVA index 2017-2020, readjust interest expenses, R\&D expenses, government subsidies and staff training expenses, and investment income to find the company's after-tax net profit from 2017 to 2020 as shown in Figure 1.

According to the regulations of the State-Owned Assets Supervision and Administration Commission and the adjustment method of this article, the company needs to adjust according to it; the calculation of the debt capital cost rate of the enterprise company capital is shown in Table 1.

4.3. Calculating the Rate of Cost of Equity Capital. Using statistical methods to find the company's $\beta$ coefficients from 2017 to 2020, according to the above explanation and the calculated $\beta$ value, find the company's cost of equity capital from 2017 to 2020 . The risk-free rate of return on the balance sheet is calculated according to the benchmark interest rate for six months to one year published by the people's Bank of China, as shown in Figure 2.

Based on the above, the EVA value of the company from 2016 to 2020 can be obtained by contacting the results of the above explanation, as shown in Table 2 .

Based on the EVA value calculated by the method in Table 2, make a 2017-2020 EVA change chart, and perform a performance analysis of the company's operating conditions, as shown in Figure 3. 


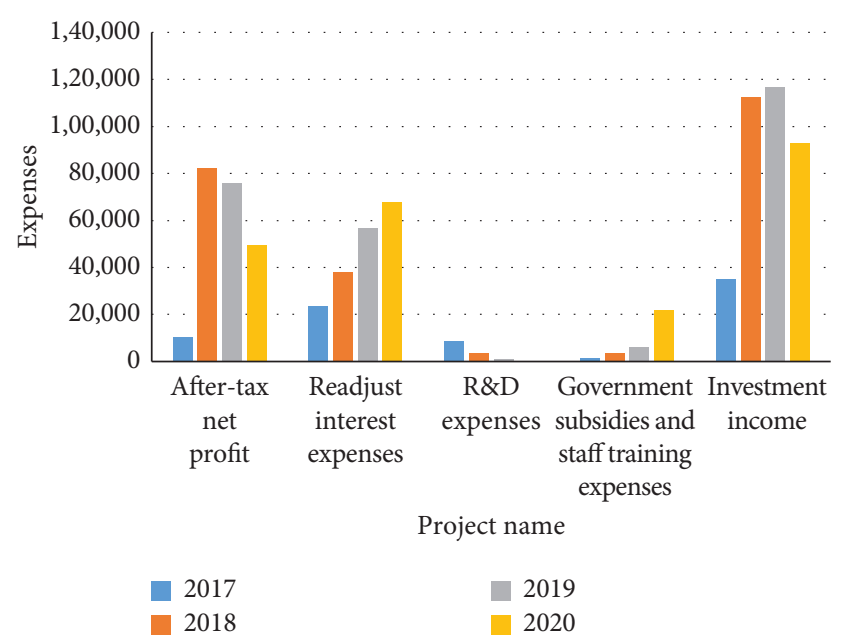

FIGURE 1: Net operating profit after tax (unit: ten thousand yuan).

TABLE 1: Loan interest rate and debt capital cost rate.

\begin{tabular}{lllll}
\hline Project name & 2017 & 2018 & 2019 & 2020 \\
Borrowing rates & $6.0 \%$ & $5.6 \%$ & $5.0 \%$ & $4.2 \%$ \\
The cost of debt capital & $4.5 \%$ & $4.5 \%$ & $3.9 \%$ & $4.3 \%$ \\
\hline
\end{tabular}

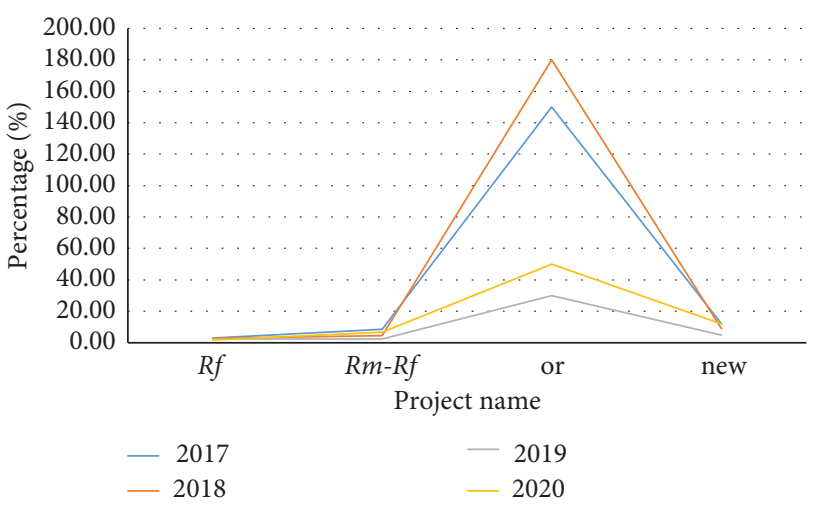

Figure 2: Cost of equity capital ratio.

From Figure 3, it is obvious that the EVA value of the company from 2017 to 2020 has a large increase in 2018 and then shows a decreasing trend, but the overall EVA value of the four years is positive. This shows that the company's capital increase in 2014 was the largest, and then the capital increase gradually decreased, but the capital increased every year for 4 years. The rapid increase in capital in 2018 should be related to the company's strategic expansion plan. In 2018, the company has a large-scale expansion in sales areas and sales. According to the increase in EVA value, EVA is a set of performance evaluation systems based on the company's strategic design, which combines the company's financial indicators and nonfinancial indicators. Business indicators are combined, starting from the company's longterm goals, and gradually decomposed into the company's short-term goals, which promote the development of the company. In the implementation of relevant performance indicators, the company's strategic objectives are taken into account to avoid the conflict between strategic objectives and short-term objectives. The construction process of the EVA performance evaluation system is shown in Table 3 .

The performance evaluation system based on EVA needs to take the company's strategy as the guidance, start from the company's mission, vision, and values; closely focus on the company's strategic focus; decompose the company's strategic objectives to the department level and staff level; and effectively promote the realization of the company's strategic objectives. The selection of EVA performance evaluation indicators should be based on actual conditions, where qualitative indicators are used when the quantification is not possible, and quantitative indicators are used when quantification is possible. The qualitative indicators and quantitative indicators are combined to achieve complementary advantages and obtain scientific and reasonable performance evaluation indicators. In the process of building a performance evaluation system, we should pay attention to its operability. A good performance evaluation system ultimately depends on good execution. Relevant indicators should be practical, concise, and easy to operate, which can not only reduce workload but also improve work efficiency and accuracy.

4.4. Index Weight Setting. According to the company content (financial dimension, customer dimension, internal business dimension, learning growth dimension) and the index weight commonly used by domestic and foreign scholars in the academic circles, set the method to construct the hierarchical model as shown in Figure 4.

Based on the analysis of the weight of each index of the four dimensions, it can be concluded that the design of the index and weight is basically in line with the overall strategic objectives of the company. Bank expects to improve its risk prevention and control ability on the basis of maintaining its current profitability. In terms of enhancing the user experience and expanding the market share, customer satisfaction and market share are relatively high in the customer dimension. The strategic goal of the internal process dimension is to standardize the business process. It is not difficult to see that its setting is consistent with the strategic goal of the enterprise by analyzing the weight of various indicators of the learning and growth dimension. That is, people-oriented, it can retain talents and improve the working ability of employees. Different industries, different capital structures, different scales, and different stages of development lead to different enterprises. The risks are different, so different industries and different investors will require different return on capital. The weighted average cost of capital ratio is different. The managers of enterprises should allocate the capital structure reasonably to improve efficiency. It can optimize the weighted average cost of capital, maximize the value of the enterprise, and then maximize the value of shareholders. The average cost of capital ratio is one of the three key factors to calculate EVA.

4.5. Balanced Scorecard. Balanced scorecard performance appraisal mechanism is mainly through the enterprise customer, operation process, finance, learning, and growth 
TABle 2: The company's EVA value from 2016 to 2020 (unit: ten thousand yuan).

\begin{tabular}{|c|c|c|c|c|}
\hline Project name & 2017 & 2018 & 2019 & 2020 \\
\hline Net operating profit after tax & 34,095 & 112,490 & 116,727 & 92,333 \\
\hline Total capital & 216,854 & $1,386,877$ & $1,127,036$ & 699,220 \\
\hline Weighted average cost of capital ratio & $11.73 \%$ & $8.90 \%$ & $4.95 \%$ & $11.78 \%$ \\
\hline EVA & 9,332 & 80,494 & 61,898 & 12,881 \\
\hline
\end{tabular}

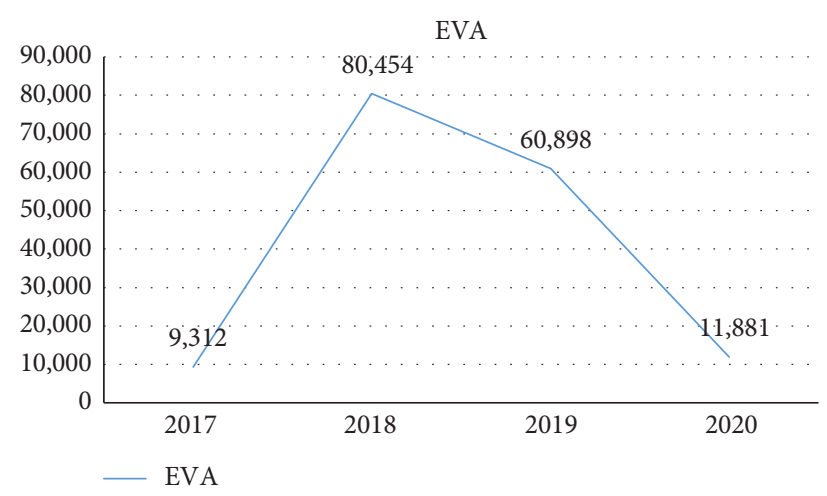

Figure 3: The company's EVA changes from 2017 to 2020.

TABLE 3: Construction process of the performance evaluation system.

\begin{tabular}{lc}
\hline Serial number & Technological process \\
\hline 1 & Define the company's mission, values, strategy \\
2 & Draw a strategic map \\
3 & Decompose the objectives layer by layer \\
4 & Establish EVA performance evaluation system \\
5 & Implement the performance plan \\
\hline
\end{tabular}

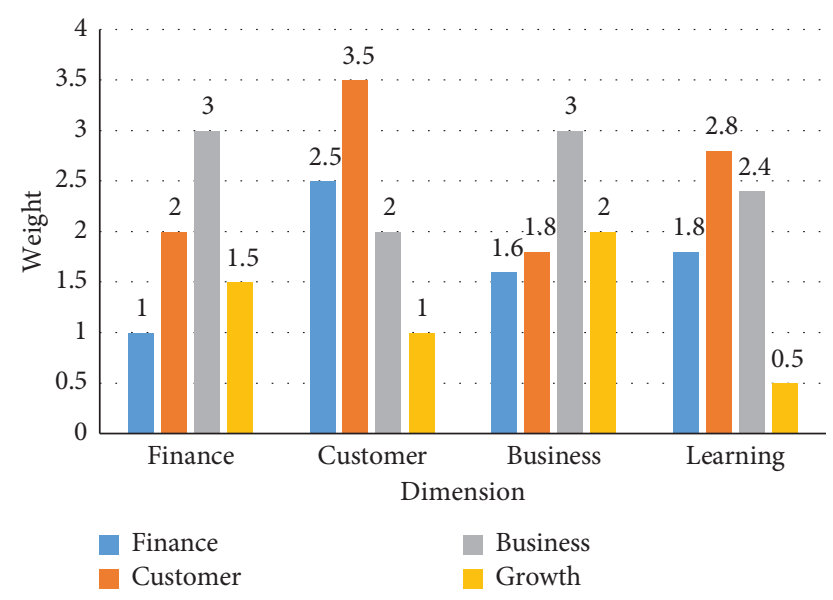

FIGURE 4: Weight index chart.

of these four aspects of in-depth discussion and the longterm strategic objectives of the enterprise level by level decomposition, to transform the company's strategy into measurable and operational indicators as shown in Figure 5.

In the process of applying a balanced scorecard, modern enterprises often combine the balanced scorecard with KPI. In the specific use, the enterprise or organization is required to subdivide the enterprise's long-term strategic objectives and enterprise's comprehensive KPI into two aspects: employee KPI and internal department KPI. Through this layer-by-layer decomposition, make the enterprise's strategic objectives into the objectives of each employee, and on this basis, carry out relevant performance evaluation of KPI. 


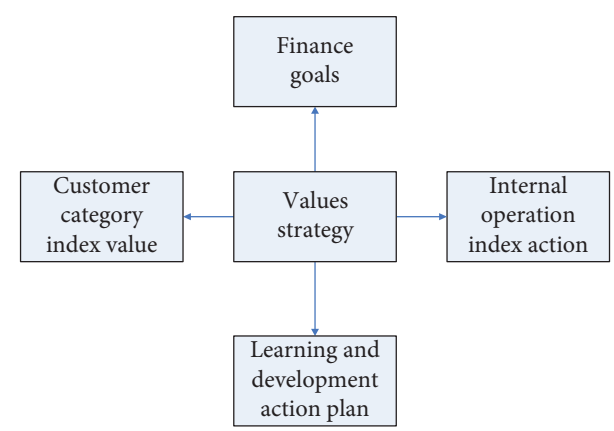

FIGURE 5: Four dimensions of the balanced scorecard.

\section{Conclusions}

This article takes EVA as the starting point of the core indicator of value maximization, decomposes it, and determines the driving factors of corporate value creation. The job of corporate managers is to create value for the company. Performance evaluation based on EVA can better use salary as an incentive. Managers create more value for the company. The comprehensive scorecard is a brand-new performance evaluation method, helps enterprises to establish effective incentive mechanisms, follow the principle of performance evaluation system construction, guided by value drivers, select the evaluation index, use the analytic hierarchy process to scientifically assign the weight of the index, formulate the evaluation method, and establish a new performance evaluation system. It helps promote internal communication, employee participation, and the development of corporate learning culture. In the process of EVA implementation, we should always pay attention to communication. Only when managers and employees at all levels have a correct understanding of the enterprise strategy and plan, they cannot conflict with the implementation of the balanced scorecard and then accept and support it. Although there are many problems in the communication mechanism of the company, in addition, due to the poor communication effect, it provides the corresponding basis for the implementation of the balanced scorecard, the company's communication mechanism can be improved in the next step to adapt to the new performance management system.

\section{Data Availability}

No data were used to support this study.

\section{Conflicts of Interest}

The authors declare that they have no conflicts of interest.

\section{Acknowledgments}

This work was supported by the University Students Innovation and Entrepreneurship Program of Zhanjiang University of Science and Technology in 2020: A Study on University Students Innovation and Entrepreneurship Tax Policy in the Context of New Crown Epidemic-A Case
Study of Foshan, Guangdong Province (project no. 2021ZKYDCA16).

\section{References}

[1] E. Berlot, N. J. Popp, and J. Diedrichsen, "In search of the engram, 2017," Current Opinion in Behavioral Sciences, vol. 20 , no. 20 , pp. 56-60, 2018.

[2] H. Carter, S. Chen, L. Isik et al., "Cancer-specific highthroughput annotation of somatic mutations: computational prediction of driver missense mutations," Cancer Research, vol. 69, no. 16, pp. 6660-6667, 2016.

[3] D. A. Maltz, J. Broch, J. Jetcheva, and D. B. Johnson, "The effects of on-demand behavior in routing protocols for multihop wireless ad hoc networks," Selected Areas in Communications IEEE Journal on, vol. 17, no. 8, pp. 14391453, 1999.

[4] E. Wisse, "The interrelation of personality, political attitudes and political behaviour: empirical findings," Trends in Cell Biology, vol. 17, no. 9, pp. 422-427, 2018.

[5] D. Visioni, G. Pitari, V. Aquila et al., "Sulfate geoengineering impact on methane transport and lifetime: results from the Geoengineering Model Intercomparison Project (GeoMIP)," Atmospheric Chemistry \& Physics, vol. 17, no. 18, pp. 1-35, 2017.

[6] L. Garcia-Prat, M. Martinez-Vicente, E. Perdiguero et al., "Autophagy maintains stemness by preventing senescence," Nature, vol. 529, no. 7607, pp. 37-42, 2016.

[7] K. E. Fleming-Dutra, A. L. Hersh, D. J. Shapiro et al., "Prevalence of inappropriate antibiotic prescriptions among US ambulatory care visits, 2010-2011," JAMA, vol. 315, no. 17, pp. 1864-1873, 2016.

[8] L. Kong, D. J. Gregg, E. R. Vance et al., "Preparation of cerium titanate brannerite by solution combustion, and phase transformation during heat treatment," Journal of the European Ceramic Society, vol. 37, no. 5, pp. 2179-2187, 2017.

[9] K. Zaremba-Niedzwiedzka, E. F. Caceres, J. H. Saw et al., "Asgard archaea illuminate the origin of eukaryotic cellular complexity," Nature, vol. 541, no. 7637, pp. 353-358, 2017.

[10] F. Jiang, D. W. Taylor, J. S. Chen et al., "Structures of a CRISPR-Cas9 R-loop complex primed for DNA cleavage," Science, vol. 351, no. 6275, pp. 867-871, 2016.

[11] C. C. Cowen and E. A. Gallardo-Gutiérrez, "A new class of operators and a description of adjoints of composition operators," Journal of Functional Analysis, vol. 238, no. 2, pp. 447-462, 2006.

[12] A. S. Kyle and A. A. Obizhaeva, "Market microstructure invariance: empirical hypotheses," Econometrica, vol. 84, no. 4, pp. 1345-1404, 2016.

[13] E. Steliarova-Foucher, M. Colombet, L. A. G. Ries et al., "International incidence of childhood cancer, 2001-10: a population-based registry study," The Lancet Oncology, vol. 18, no. 6, pp. 719-731, 2017.

[14] S. Yusuf, E. Lonn, P. Pais et al., "Blood-pressure and cholesterol lowering in persons without cardiovascular disease," New England Journal of Medicine, vol. 374, no. 21, pp. 2032-2043, 2016.

[15] T. Tabata, M. Petitt, H. Puerta-Guardo et al., "Zika virus targets different primary human placental cells, suggesting two routes for vertical transmission," Cell Host \& Microbe, vol. 20, no. 2, pp. 155-166, 2016.

[16] E. Krapohl, J. Euesden, D. Zabaneh et al., "Phenome-wide analysis of genome-wide polygenic scores," Molecular Psychiatry, vol. 21, no. 9, pp. 1188-1193, 2016. 
[17] B. D. Cheson, W. Brugger, G. Damaj et al., "Optimal use of bendamustine in hematologic disorders: treatment recommendations from an international consensus panel-an update," Leukemia \& Lymphoma, vol. 57, no. 4, pp. 766-782, 2016.

[18] E. Lindholm, L. Cavelier, W. M. Howell et al., "Mitochondrial sequence variants in patients with schizophrenia," European Journal of Human Genetics, vol. 5, no. 6, pp. 406-412, 1997.

[19] R. Pop-Busui, A. J. M. Boulton, E. L. Feldman et al., "Diabetic neuropathy: a position statement by the American diabetes association," Diabetes Care, vol. 40, no. 1, pp. 136-154, 2017.

[20] L. J. Pankhurst, C. Del Ojo Elias, A. A. Votintseva et al., "Rapid, comprehensive, and affordable mycobacterial diagnosis with whole-genome sequencing: a prospective study," The Lancet Respiratory Medicine, vol. 4, no. 1, pp. 49-58, 2016. 